\title{
Prevalence of ENT Diseases in the Mental Deficient Patients
}

\section{Ndadi Tchiengang Kadielle Junie ${ }^{1 *}$, Adama Koundoul ${ }^{2}$, Kizonde Kalungwe Yannick ${ }^{3}$, Diom Siga Evelyne ${ }^{1}$}

${ }^{1}$ ENT and CCF Department, Peace Hospital, Ziguinchor, Senegal

${ }^{2}$ Emile Badiane Psychiatric Center, Ziguinchor, Senegal

${ }^{3}$ ENT and CCF Department, Dakar-Senegal "Principal” Hospital, Dakar, Senegal

Email: *Juniekadie@gmail.com

How to cite this paper: Junie, N.T.K., Koundoul, A., Yannick, K.K. and Evelyne, D.S. (2021) Prevalence of ENT Diseases in the Mental Deficient Patients. International Journal of Otolaryngology and Head \& Neck Surgery, 10, 229-237.

https://doi.org/10.4236/ijohns.2021.103021

Received: April 19, 2021

Accepted: May 24, 2021

Published: May 27, 2021

Copyright $\odot 2021$ by author(s) and Scientific Research Publishing Inc. This work is licensed under the Creative Commons Attribution International License (CC BY 4.0).

http://creativecommons.org/licenses/by/4.0/

\begin{abstract}
Introduction: Patients with mental deficiency have increased health needs. They develop certain ailments more than the rest of the general population. ENT pathology includes all the ailments concerning the nose, throat and ear and is a frequent reason for consultation in our health facilities. The aim of this study was to report the prevalence of ENT diseases in mental deficient. Material and Methods: This was a prospective, longitudinal study on a population of patients received in ENT consultation, during the days of October 15, 2019 and February 18, 2020 on the occasion of health campaigns organized by the Senegal Special Olympics Association. All admitted patients were mental deficient. Results: Out of a total of 334 patients received in general consultation (all specialties combined), 61 patients underwent an ENT consultation, i.e. a prevalence of $18.26 \%$. There were more men $(\mathrm{N}=39)$ than women $(\mathrm{N}=32)$. The average age of the patients was 20 years. A past history of chronic otitis media was reported in $9.83 \%$ of patients $(\mathrm{N}=6)$. Functional signs were dominated by hypoacusis $(\mathrm{N}=16)$. Seventy point forty-nine patients $(\mathrm{N}=43)$ had otologic conditions. Thirty-four patients had trisomy 21 (64.15\%). Conclusion: The prevalence of ENT diseases among the mental deficient is considerable. This study is the first of its type in Senegal which superimposes the ENT on mental deficiency.
\end{abstract}

\section{Keywords}

ENT, Mental Deficiency, Ziguinchor

\section{Introduction}

Mental deficiency or mental handicap is defined as a significant decrease in in- 
tellectual capacities associated with a limitation of adaptive faculties in various sectors such as communication, autonomy, learning school, social life, individual responsibility, work, leisure and health [1]. There is a close relationship between mental deficiency and health [2]. In fact, people with disabilities have much higher medical needs than the general population [3] [4] [5]. Several studies have shown that physical health problems in this category of patients are underdiagnosed [4]. Mental deficiency concerns 1 to $3 \%$ of the population [6]. The causes are multiple [2] and can lead to recurrent pathologies, in this case those of the ENT sphere. ENT pathology includes all the affections of the nose, throat and ears. If it constitutes a frequent reason for consultation in the general population [7], studies also show a high prevalence of certain affections, associated disorders and certain ENT pathologies in mental deficient people [8] [9]. Mental deficiency is a public health problem [6]. In Senegal, the mental deficient situation is worrying [10]. According to a document from the ANDS (National Agency for Demography and Statistics), among children with various disabilities listed in Senegal, mental deficiency affects one in ten children [11]. We conducted a study in Ziguinchor in the south of Senegal whose goal was to determine the prevalence of ENT diseases in mentall deficient people. The secondary objective was to determine whether some mental deficient patients developed more ENT pathologies than others.

\section{Patients and Method}

This is a prospective, longitudinal study on a population of patients received in ENT consultations on October 15, 2019 and November 18, 2020 during free health campaigns organized by the Special Olympicsassociation-Senegal. It is a non-profit association that contributes to improving the health of people with mental disabilities [12]. The Djignabo high school served as a consultation unit in Ziguinchor, a town located $450 \mathrm{~km}$ from Dakar. In this study, we only included the patients with mental deficiency received in ENT consultation on these days.

An intelligence quotient (IQ) less than 69, limitations in two or more areas of adaptive functioning (communication, personal care, household skills, social skills, independence, health and safety), diagnostic signs present before the age of 18 , are parameters taken into account in the diagnosis of mental deficiency. IQ is therefore not the only criterion taken into account to determine mental deficiency, especially at an early age where it is not easy to establish. There are actually very few intellectual assessments before school age. For young children, assessments based on the child's development are preferred, for example Piaget (for infants) and Brunet-Lezine (for 2 to 3 years). These are fairly old tests but still in use [2].

For each patient received we proceeded to an interview. The patients' parents or accompanying persons were intermediaries. Then we carried out the clinical examination. We established consultation forms on which we had recorded all the anamnestic and clinical information of each patient. Information was col- 
lected from these consultation forms. The studied variables were grouped into epidemiological, clinical and etiological parameters. They were sex, age, past history, reason for consultation, site of the damage, diagnosis made and etiology of mental deficiency.

The data from this study were analyzed and coded using the Epi Info version 7.7.2 software. The charts were constructed using Microsoft Office Excel 2013 and SPSS software.

\section{Ethical Considerations}

For this prospective study, the free and informed consent of the parents and accompanying persons of each patient was required and recorded in writing, The confidentiality of the data was preserved.

\section{Results}

\subsection{Epidemiological Aspects}

Sixty-one patients were received in ENT consultation out of a total of 334 patients received in general consultation (all specialties combined), i.e. a prevalence of $18.26 \%$. There were 22 women versus 39 men for a sex ratio of 1.77 . The average age of the patients was 20 years with extremes of 4 years and 36 years.

Thirty-one point fourteen percent of the patients $(\mathrm{N}=19)$ were between 10 years and 15 years old (Table 1 ).

A past history of chronic otitis media was reported in $9.83 \%(\mathrm{~N}=6)$ (Table 2).

\subsection{Clinical Aspects}

Nineteen patients had come without an apparent reason for consultation (31.14\%). The actual functional signs were dominated by hypoacusis (26.22\%) (Table 3 ).

The ear was the organ of the ENT sphere mainly affected (63.93\%) (Figure 1). Ear pathologies were predominant (Table 4).

\subsection{Etiological Aspects}

We were able to determine the etiology of mental deficiency in 53 patients (86.88\%). Trisomy 21 was the most common etiology in 34 patients (64.15\%) (Table 5).

Table 1. Distribution of patients by age group.

\begin{tabular}{ccc}
\hline Age group (year) & Number of patients & Percentage \\
\hline$[4-9]$ & 16 & 26.22 \\
{$[10-15]$} & 19 & 31.14 \\
{$[16-21]$} & 13 & 21.31 \\
{$[22-27]$} & 7 & 11.46 \\
{$[28-33]$} & 3 & 4.92 \\
{$[34-36]$} & 3 & 4.92 \\
Total & 61 & 100
\end{tabular}


Table 2. Antecedents.

\begin{tabular}{ccc}
\hline Antecedent & Number of patients & Percentage \\
\hline Prematurity & 3 & 4.92 \\
Epilepsy & 3 & 4.92 \\
Recurrent otitis & 6 & 9.83 \\
Meningitis & 2 & 3.22 \\
Fetal suffering & 8 & 13.11 \\
Growth retardation & 37 & 60.65 \\
Cesarean birth & 2 & 3.28 \\
Total & 61 & 100 \\
\hline
\end{tabular}

Table 3. Functional signs.

\begin{tabular}{ccc}
\hline Reason for consultation & Number of patients & Percentage \\
\hline None & 19 & 31.14 \\
Glossodynia & 1 & 1.63 \\
Hearing loss & 16 & 26.22 \\
Nasal obstruction & 3 & 4.92 \\
Nasal/ear pruritus & 7 & 11.46 \\
Sneeze & 3 & 4.92 \\
Language disorder & 8 & 13.11 \\
Otalgia & 9 & 14.75 \\
Rhinorrhea & 6 & 9.83 \\
Otorrhea & 3 & 4.92 \\
\hline
\end{tabular}

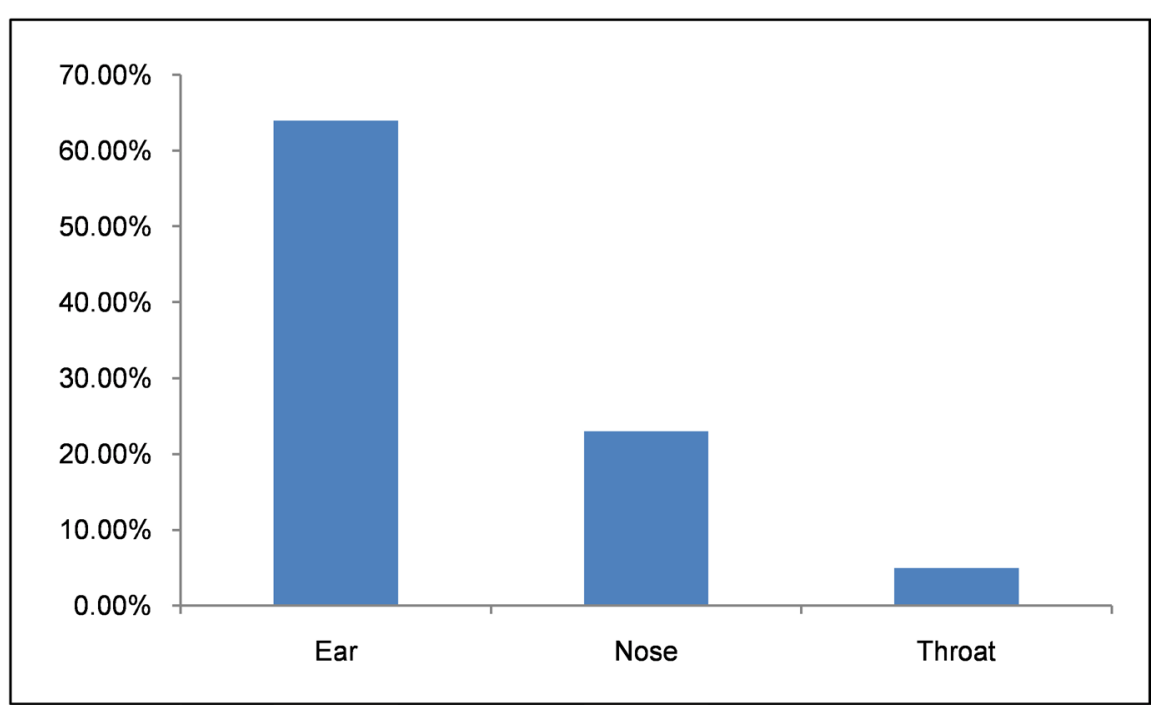

Figure 1. Distribution of patients according to the site of the disease. 
Table 4. Prevalence of ENT pathologies.

\begin{tabular}{ccc}
\hline Diagnostics & Number of patients & Percentage \\
\hline Glossitis & 1 & 1.63 \\
Cleft palate & 1 & 1.63 \\
Allergic rhinitis & 11 & 18.03 \\
Foreign bodies in the external ear & 2 & 3.27 \\
Nasopharyngitis & 4 & 6.55 \\
Earwax plugs & 15 & 24.59 \\
Deafness & 7 & 11.47 \\
Acute otitis media & 2 & 3.27 \\
Gastroesophageal reflux & 1 & 1.63 \\
Sero-mucous otitis & 1 & 1.63 \\
Chronic otitis media & 14 & 22.95 \\
External otitis & 2 & 3.27 \\
Total & 61 & 100 \\
\hline
\end{tabular}

Table 5. The different etiologies of mental retardation.

\begin{tabular}{ccc}
\hline Etiology & Number of patients & Percentage \\
\hline Trisomy 21 & 34 & 64.15 \\
Epilepsy & 3 & 5.66 \\
Prematurity & 3 & 5.66 \\
Méningite & 2 & 3.77 \\
fetal distress & 8 & 15.09 \\
Cerebral palsy & 3 & 5.66 \\
\hline
\end{tabular}

\section{Discussion}

\subsection{Epidemiological Aspect}

We collected 61 patients in ENT consultation out of a total of 334 patients. This prevalence of $18.26 \%$ shows the considerable relationship between mental deficiency and ENT.

Morin [4] and Lelli [13] reported male predominance. However, Wagalo [13] achieved a female predominance in her series.

There is a disparity between the predominant age group in our series and those obtained in the literature [4] [13].

This could be explained by the fact that in the studies, the age inclusion criteria differ. In our study, we included all ages received.

The only ENT past history reported was chronic otitis media. We were unable to compare our result with those of other authors because of the studies' scarcity conducted on the subject. 


\subsection{Clinical Aspects}

Thirty-one percent of patients had no reason for consultation. They had come for an ENT consultation because it was free. These consultations, organized at least once a year, are for most patients the only opportunity to see a specialist, especially an ENT specialist. The reason given is that people with disabilities have poor access to health services [2]. Baxter [14] also reported that $51 \%$ of the patients in his cohort had a medical condition that was previously undiagnosed.

The medical care needs of people with intellectual disabilities are significantly higher than those of the general population [8]. Studies agree that comorbidity is more common in people with intellectual disabilities than the general population (Table 6) [15] [16] [17] [18].

Patients with mental deficiency develop more ENT problems than those in the general population (Table 7) [19].

Table 6. Prevalence rate of people with ID vs. general population [18].

\begin{tabular}{|c|c|c|}
\hline Health problems & $\begin{array}{c}\text { Rate of people } \\
\text { with ID (\%) }\end{array}$ & $\begin{array}{l}\text { Rate of general } \\
\text { population (\%) }\end{array}$ \\
\hline Congenital disorders & 5.0 & 0.4 \\
\hline Epilepsy & 11.0 & 0.8 \\
\hline Disability/impairment musculo-skeletal & 6.0 & 0.5 \\
\hline Strabismus & 5.3 & 1.1 \\
\hline Premature/immature liveborn infant & 4.1 & 0.9 \\
\hline Others central nervous system disorders & 4.4 & 1.1 \\
\hline All perinatal morbidities & 5.3 & 1.5 \\
\hline Obesity & 8.8 & 3.5 \\
\hline Lower leg fracture & 5.0 & 1.9 \\
\hline Congenital musculo skeletal system abnormalities & 3.1 & 1.3 \\
\hline Acne & 4.1 & 1.6 \\
\hline Contact dermatitis or Other eczema & 5.7 & 2.9 \\
\hline Hemorrhoids & 3.5 & 1.8 \\
\hline Overweight & 4.1 & 2.3 \\
\hline Undescended testicles & 3.6 & 1.3 \\
\hline
\end{tabular}

Table 7. Comparison between the prevalence of ENT diseases in people with MD and the general population.

\begin{tabular}{ccc}
\hline ENT pathology & $\begin{array}{c}\text { Prevalence in people } \\
\text { with DM (\%) }\end{array}$ & $\begin{array}{c}\text { Prevalence in the } \\
\text { normal population (\%) }\end{array}$ \\
\hline Hyperthophy/chronic infection tonsils/adenoid & 11.0 & 7.0 \\
Deafness & 6.3 & 2.3 \\
Hypothyroidism & 5.7 & 3.2 \\
Glue ear & 3.1 & 1.7 \\
\hline
\end{tabular}


We have reported more ENT pathologies in mental deficient people than other studies have reported. Unlike ours, these studies framework was much more general.

However, we have not reported cases of hypothyroidism and tonsillar infections. In our study, ear conditions were in the majority.

\subsection{Etiological Aspects}

Trisomy 21 is the most common genetic cause of mental deficiency, i.e. $22 \%$ of known causes [13]. In the present study, trisomy 21 was the predominant etiology of mental deficiency in ENT consultation.

\subsection{Limitations of the Study}

Although our study was prospective, we encountered difficulties. Some mothers or accompanying persons gave us insufficient information on the patients' medical history. There was also sometimes insufficient documentation on the etiology of mental deficiency.

\subsection{Perspective for Future Study}

We found a rate of trisomy 21 clearly superior to certain data in the literature. Most of these patients had been seen for the first year and then seen for the second year in a row. A study on the profile of ENT pathologies in patients with trisomy 21 could be envisaged.

\section{Conclusion}

The ENT disease prevalence among the mental deficient is considerable. Patients with MD have increased health needs. They develop certain ENT pathologies more than the rest of the general population. However, this patient population has difficulty accessing health care and faces underdiagnosis. These difficulties and inequalities contrast with their health needs, whether they are common or specific to certain pathologies. The State must be strongly involved by integrating them into the health system. Associations also play an important role in the treatment of these patients, as they multiply medical campaigns by giving the disabled the opportunity to access specialized consultations. Psychiatrists must play an important role as an intermediary between the specialty services and these particular patients, very often misunderstood.

\section{Conflicts of Interest}

The authors declare no conflicts of interest regarding the publication of this paper.

\section{References}

[1] Lyon, G. and Evrard, P. (2000) Neuropediatrics. 2nd Edition, Masson, Paris.

[2] Bartholome, C., et al. (2009) The Inclusion of Children with Disabilities in Early 
Childhood Care Settings. Training Guide for Professionals Working in Early Childhood 0-3 Years.

https://www.fileasbl.be/membres/wp-content/uploads/2015/12/FILE_Guide-inclusi on.pdf

[3] Henry, K. and Cheung, P.W.H. (2007) Co-Morbidity of Psychiatric Disorder and Medical Illness in People with Intellectual Disabilities. Current Opinion in Psychiatry, 20, 443-449. https://doi.org/10.1097/YCO.0b013e3282ab9941

[4] Morin, D., Mérineau-Côté, J., Ouellette-Kuntz, H., Tassé, M.J. and Kerr, M. (2012) A Comparison of the Prevalence of Chronic Disease among People with and without Intellectual Disability. American Journal on Intellectual and Developmental Disabilities, 117, 455-463. https://doi.org/10.1352/1944-7558-117.6.455

[5] Buntinx, W., Cans, C., Colleaux, L., Courbois, Y., Debbané, M., et al. (2016) Déficiences intellectuelles. [Rapport de recherche] Institut national de la santé et de la recherche médicale(INSERM). 2016, Paris: Inserm: Editions EDP Sciences (ISSN: 1264-1782), 1420.

[6] Héron, D. and Jacquette, A. (2009) How to Explore an Intellectual Disability in Adults? Neurologie.com, 1, 219-222. https://doi.org/10.1684/nro.2009.0111

[7] Abdel, D. (2015) Profile of ENT Consultations in the Provinces. Case of Sissako Hospital: Epidemiological, Clinical and Therapeutic Aspects. University of Bamako, Bamako.

[8] ANESM: National Agency for the Assessment and Quality of Social and Medico-Social Establishments and Services (2017) Quality of Life: Handicap, Somatic Problems and Painful Phenomena. Guide to identifying somatic problems.

https://www.has-sante.fr/upload/docs/application/pdf/2018-03/guide_des_problem es_somatiques.pdf

[9] Artières, F. and Niango, G. (2010) ENT Pathologies and Trisomy 21. https://www.reseau-maladies-rares.fr/uploads/Les_pathologies_ORL.pdf

[10] Sall, A. (2008) Treatment of the Mental Deficient Children Treated at Keur Xaleyi (Centre National Hospitalier Universitaire de Fann). Advanced Studies Diploma Thesis. Faculty of Letters and Human Sciences. Cheikh Anta Diop University, Dakar.

[11] RGPH 3, National Results Presentation Report, ANDS. December 2006, p.72. http://www.ansd.sn/ressources/rapports/RGPH3_RAP_NAT.pdf

[12] Special Olympics Senegal. Who Are We?-Special Olympics Senegal. https://www.specialolympics.sn/qui-sommes-nous/

[13] Safiatou, L. (2009) Study of Mental Deficiency in Children Aged 3 to 60 Months. Doctoral Thesis in Medicine. FMPOS. University of Bamako, Bamako.

[14] Baxter, H., Lowe, K., Houston, H., Jones, G., Felce, D. and Kerr, M. (2006) Previously Unidentified Morbidity in Patients with Intellectual Disability. British Journal of General Practice, 56, 93-98.

[15] Cooper, S.A. and Bailey, N.M. (2001) Psychiatric Disorders amongst Adults with Learning Disabilities: Prevalence and Relationship to Ability Level. Irish Journal of Psychological Medicine, 18, 45-53. https://doi.org/10.1017/S0790966700006315

[16] Janicki, M.P., Davidson, P.W., Henderson, C.M., et al. (2002) Health Characteristics and Health Services Utilization in Older Adults with Intellectual Disability Living in Community Residences. Journal of Intellectual Disability Research, 46, 287-298. https://doi.org/10.1046/j.1365-2788.2002.00385.x

[17] O'Brien, G. (2001) Defining Learning Disability: What Place Does Intelligence Testing Have Now? Developmental Medicine \& Child Neurology, 43, 570-573. 
[18] van Schrojenstein Lantman-de Valk, H.M.J., Metsemakers, J.F.M., Haveman, M.J. and Crebolder, H.F.J.M. (2000) Health Problems in People with Intellectual Disability in General Practice: A Comparative Study. Family Practice, 17, 405-407. https://doi.org/10.1093/fampra/17.5.405

[19] Jansen, D.E.M.C., Krol, B., Groothoff, J.W. and Post, D. (2004) People with Intellectual Disability and Their Health Problems: A Review of Comparative Studies. Journal of Intellectual Disability Research, 48, 93-102.

https://doi.org/10.1111/j.1365-2788.2004.00483.x 